\title{
Co-pyrolysis of corn cobs and polypropylene for production of biofuel similar to gasoline at low heating rate
}

\author{
Dijan Supramono ${ }^{1}$, Fianna Utomo $^{1}$, Setiadi $^{1}$, Mohammad Nasikin ${ }^{1 *}$ \\ ${ }^{1}$ Department of Chemical Engineering, Faculty of Engineering, Universitas Indonesia, Depok 16424, Indonesia
}

\begin{abstract}
Co-pyrolysis between corncobs and polypropylene has a synergetic effect that transforms part of polar fraction of bio-oil into non-polar fraction containing non-oxygenate compounds as precursor for synthesis of bio-fuel. In the present work, pyrolysis of the nonpolar fraction of bio-oil was led to produce bio-oil with viscosity similar to that of gasoline and contained non-oxygenated compounds. The pyrolysis was carried out in 2 stages, where the first-stage was co-pyrolysis to produce non-polar bio-oil and the second-stage was pyrolysis of non-polar fraction from the first stage to reduce its viscosity similar to that of gasoline. The first and second-stage pyrolysis was carried out in a stirred tank reactor at heating rate of $5^{\circ} \mathrm{C} / \mathrm{min}$ using nitrogen as carrier gas with the second-stage pyrolysis final temperature varied. The resulting bio-oil product was characterized by FT-IR, GC-MS, $\mathrm{H}-\mathrm{NMR}$, viscometer and LC-MS. The results show that bio-oil viscosity and yield of the second-stage pyrolysis heavily depended on its final temperature, in which the higher the temperature, the higher was the viscosity, yet the higher was the bio-oil yield. Final temperature of $300^{\circ} \mathrm{C}$ was the optimal one for obtaining bio-oil similar to gasoline regarding its close viscosity despite of low yield of bio-oil. Pyrolysis of bio-oil may be performed coinciding with attempting of reducing branching index to reduce its viscosity.
\end{abstract}

\section{Introduction}

In 2015, Indonesia imported energy around $27 \%$ from the total primary energy. The oil production development tends to decrease from 287.30 million barrels to 251.87 million barrels. On the other hand, consumption rate of fuel oil continues to increase. The increase of fuel consumption goes along with economic and population growth whilst the production of raw oil decrease [1].

Corncobs biomass has a high potential to be developed as a source of bio-oil. There are a lot of corncobs from maize waste produced by tropical countries. In Indonesia alone, in 2010, the waste produced from maize waste was 17,826 tons [2]. The pyrolysis of corncobs can produce bio-oils which by hydrogenation process will be able to be used as biofuel either as gasoline or diesel.

Co-pyrolysis between polypropylene plastics and biomass has been researched before and produced low oxygenated bio-oil with higher yields. By using a stirred tank reactor to maximize the heat transfer, the process can be achieved. Co-pyrolysis of polypropylene and corn cobs inside stirred tank reactor also produced two separated phase of bio-oil, in which the top part is a nonoxygenated (non-polar) phase and the bottom phase is an oxygenated (polar) phase [3]. The non-polar phase can be used as bio-oil as precursor of diesel engine as it does not have any oxygenate compounds [4]. However, the non-polar phase cannot be used as gasoline as its viscosity is much more similar to diesel.

Several works have been performed to produce biooil that can be used. Boucher et.al. have done a pyrolysis of softwood bark by adding methanol to achieve bio-oil that can be used as gas turbine fuel [5]. Kumar and Singh pyrolyzed HDPE pellets to achieve bio-oil with kinematic viscosity 3,3 cSt [6]. The viscosity of bio-oil from previous works had been more similar to that of diesel fuel. A research of non-catalytic co-pyrolysis with the purpose of making bio-oil with characteristics close to gasoline is hardly found.

The aim of the present research is to obtain bio-oil that has similar characteristics to gasoline's, so it can be used for internal combustion engines. To produce a biooil with viscosity and characteristics similar to gasoline, it has been proposed to do two stages of pyrolysis in a stirred tank reactor. The first-stage pyrolysis produced non-oxygenated bio-oil with viscosity similar to diesel. The second-stage pyrolysis was used to further break down the hydrocarbon chains of the first-stage bio-oil to produce expectedly shorter chains of hydrocarbons.

\section{Experimental Setup}

Corresponding author: mnasikin@che.ui.ac.id 
The pyrolysis was carried out in 2 stages, where the first stage was co-pyrolysis of corn cobs and polypropylene to produce non-polar bio-oil and the second stage was pyrolysis of non-polar fraction from the first stage to do more cracking of the first-stage bio-oil product in order to reduce its viscosity leading to that of gasoline. The copyrolysis was conducted in a stirred tank reactor with mass composition of corn cobs and polypropylene respectively $12.5 \%$ and $87.5 \%$ in the feed mixture. Polypropylene was used as a hydrogen donor due to its higher hydrogen to carbon mole ratio compared to that of biomass and can partly provide hydrogen to and partly remove oxygen from biomass pyrolysis products [7]. This allows synergetic effect to produce more nonoxygenated bio-oil by removing oxygen into noncondensable gas composing mostly $\mathrm{CO}, \mathrm{CO}_{2}$ and into bio-oil as $\mathrm{H}_{2} \mathrm{O}$ [8]. This feed composition was selected because it produced the highest yield of non-polar bio-oil and the aliphatic composition of the bio-oil was similar to that obtained by co-pyrolysis using any feed mixture containing more than $50 \%$ polypropylene [3].
Corn cob particles were obtained from agricultural waste dump in Bogor, Indonesia and sieved to particle sizes of $500 \mu \mathrm{m}-1 \mathrm{~mm}$. The particles were then dried in an oven to achieve moisture content $\leq 10 \%$. The copyrolysis reactor containing corn cob particles and polypropylene granules was heated from ambient temperature to $500^{\circ} \mathrm{C}$, with heating rate of $5^{\circ} \mathrm{C} / \mathrm{min}$ and holding time of 10 minutes at constant temperature of $500^{\circ} \mathrm{C}$. Nitrogen gas was used as carrier gas. The pyrolytic vapor was condensed with a series of two water-cooled bulb condensers and the bio-oil product were collected in a container. Circulating cooling water at $15^{\circ} \mathrm{C}$ or less was used for the condensers [9].

The second-stage pyrolysis was conducted in the same reactor with the same conditions except that the final temperature was varied. There were five bio-oil samples obtained from the co-pyrolysis, respectively named as non-polar bio-oil $87.5 \%$ PP (a) to (e). Nonpolar bio-oil $87.5 \% \mathrm{PP}$ (a) was used for TGA analysis to get its mass decomposition characteristic. Non-polar biooil $87.5 \%$ PP (b) to (e) were used as feeds for the secondstage pyrolysis.

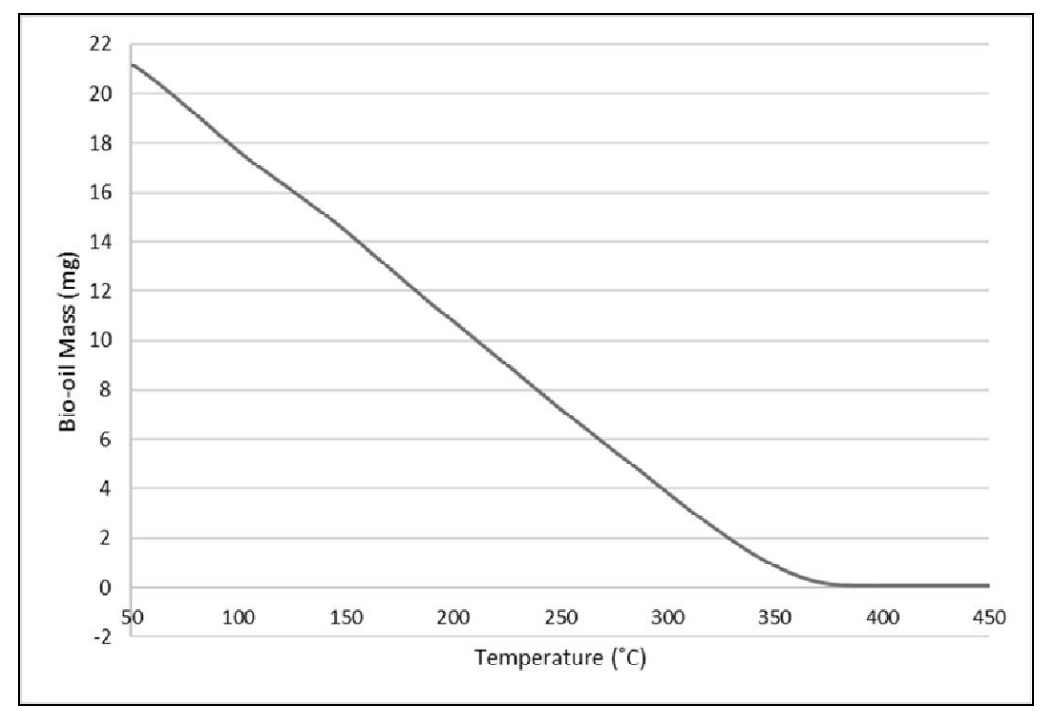

Fig. 1. TGA result of $87.5 \% \mathrm{PP}$ bio-oil

A $5 \mathrm{ml}$ of the non-polar bio-oil sample were pyrolyzed in a thermogravimetric analyzer (TGA), with the heating rate of $5^{\circ} \mathrm{C} / \mathrm{min}$ until temperature of $600^{\circ} \mathrm{C}$. Nitrogen flow used in the TGA was $50 \mathrm{ml} / \mathrm{min}$. The TGA result is exhibited in Fig. 1. The figure implies that the heaviest decomposed mass of the sample under heating rate of $5^{\circ} \mathrm{C} / \mathrm{min}$ evaporated at $375^{\circ} \mathrm{C}$. By comparison, the highest boiling point of gasoline is $200^{\circ} \mathrm{C}$. It means that the pyrolysis of the bio-oil obtained from the first-stage pyrolysis needs more fragmentation to obtain bio-oil with the heaviest molecules having boiling point about $200^{\circ} \mathrm{C}$. Four variations of secondstage pyrolysis final temperatures were selected. i.e. $200^{\circ} \mathrm{C}, 300^{\circ} \mathrm{C}, 375^{\circ} \mathrm{C}$ and $450^{\circ} \mathrm{C}$, which used non-polar bio-oil $87.5 \% \mathrm{PP}(\mathrm{b}),(\mathrm{c}),(\mathrm{d})$ and (e) resulting from the first-stage pyrolysis as feeds.

The second-stage pyrolysis was run in a stirred tank reactor and at the same operational conditions for all feeds, holding time kept for 30 minutes, but the final temperature was varied. The bio-oil samples from the second-stage pyrolysis were then analyzed using viscometer, GC-MS, LC-MS and H-NMR.

The characteristics of bio-oil samples were then compared to gasoline characteristics based on the kinematic viscosity, branching index (BI), and higher heating value (HHV). The branching index was calculated using H-NMR data and by Eq. 1 [10], where $\mathrm{S}_{\mathrm{CH}_{3}}$ is the \% amount of protons in $\mathrm{CH}_{3}$ and $\mathrm{S}_{\mathrm{CH}_{2}+\mathrm{CH}}$ is the sum of $\%$ amount of protons in $\mathrm{CH}_{2}$ and $\mathrm{CH}$. Higher $\mathrm{BI}$ value indicates that the carbon chain has more branches [11].

$$
\mathrm{BI}=\frac{\left[\left(\frac{1}{3}\right) \mathrm{s}_{\mathrm{CH}_{3}}\right]}{\left[\left(\frac{1}{2}\right) \mathrm{s}_{\mathrm{CH}_{2}+\mathrm{CH}}\right]}
$$


Meanwhile the higher heating value was calculated by Eq. 2 [12]. The values of $\mathrm{HHV}$ in $\mathrm{MJ} / \mathrm{kg}$ were also calculated by using H-NMR data.

$$
\begin{aligned}
& H H V=0.3491 C+1.1783 H+0.1005 S-0.1034 O- \\
& 0.0151 N-0.0211 \mathrm{~A}(\mathrm{MJ} / \mathrm{kg})
\end{aligned}
$$

where $C, H, S, O, N$ and $A$ were the mass fraction of atoms carbon, hydrogen, sulphur, oxygen, nitrogen and ash, respectively.

\section{Results and Discussion}

\subsection{First-Stage Pyrolysis Bio-oil Characterization}

Bio-oil from the first-stage pyrolysis was characterized using FT-IR, GC-MS and H-NMR. The FT-IR result is shown in Fig. 2. The figure shows that the spectra are identical among different products of bio-oil. The main types of carbon chains identified by FTIR were alkanes, alkenes, and cyclohexyl.

To support the FT-IR result, the bio-oil was analyzed by GC-MS to see detailed compound composition. The result is shown in Fig. 3. The type of carbon chain dominating the composition of all bio-oil samples was alkenes. The other carbon chains detected were alkanes, cycloalkanes, cycloalkenes and oxygenates. Due to similarity patterns of FT-IR and GC-MS data among 4 samples of bio-oil, bio-oil obtained from different runs of the first-stage pyrolysis can be considered to have one bio-oil characteristic. This also demonstrates the repeatability of stirred tank reactor results.
The H-NMR result can be seen in the third column of Table 1, where the combined proton composition of methyl, methylene and methyne which represents proton composition in saturated C-C bonds is about $75 \%$. It means that majority of aliphatic groups was of alkanes. This is contrary to the result exhibited by GCMS where the majority of the groups was of alkenes. Sharypov et al [13] and Nanda et al [14] have revealed that GCMS is capable of identifying molecular structures of compounds up to a limited molecular weight. Therefore, data shown in Fig. 3 was restricted to low molecular weight compounds in the bio-oil. GCMS may be able to identify functional groups and types of carbon chains but cannot quantify their compositions in the bio-oil. This result also indicates that alkene compounds may have been mostly as low molecular compounds.

\subsection{Second-Stage Pyrolysis Yields}

The bio-oil yields in the second-stage pyrolysis are shown in Fig. 4. The bio-oil yield increased as the final temperature of the pyrolysis was increased. This result may be in contrary to what is expected that the higher the final temperature, the lower was the bio-oil yield. The second-stage pyrolysis produced bio-oil which has different characteristics from the bio-oil feed and noncondensable gas. The fashion of Fig. 4 indicates that at higher final temperature, small radicals produced had a tendency to undergo polymerization rather than being combined to produce non-condensable gas. This possibility has also been found by Vinu et al [15]. Indications towards polymerization will be elucidated in following sections.

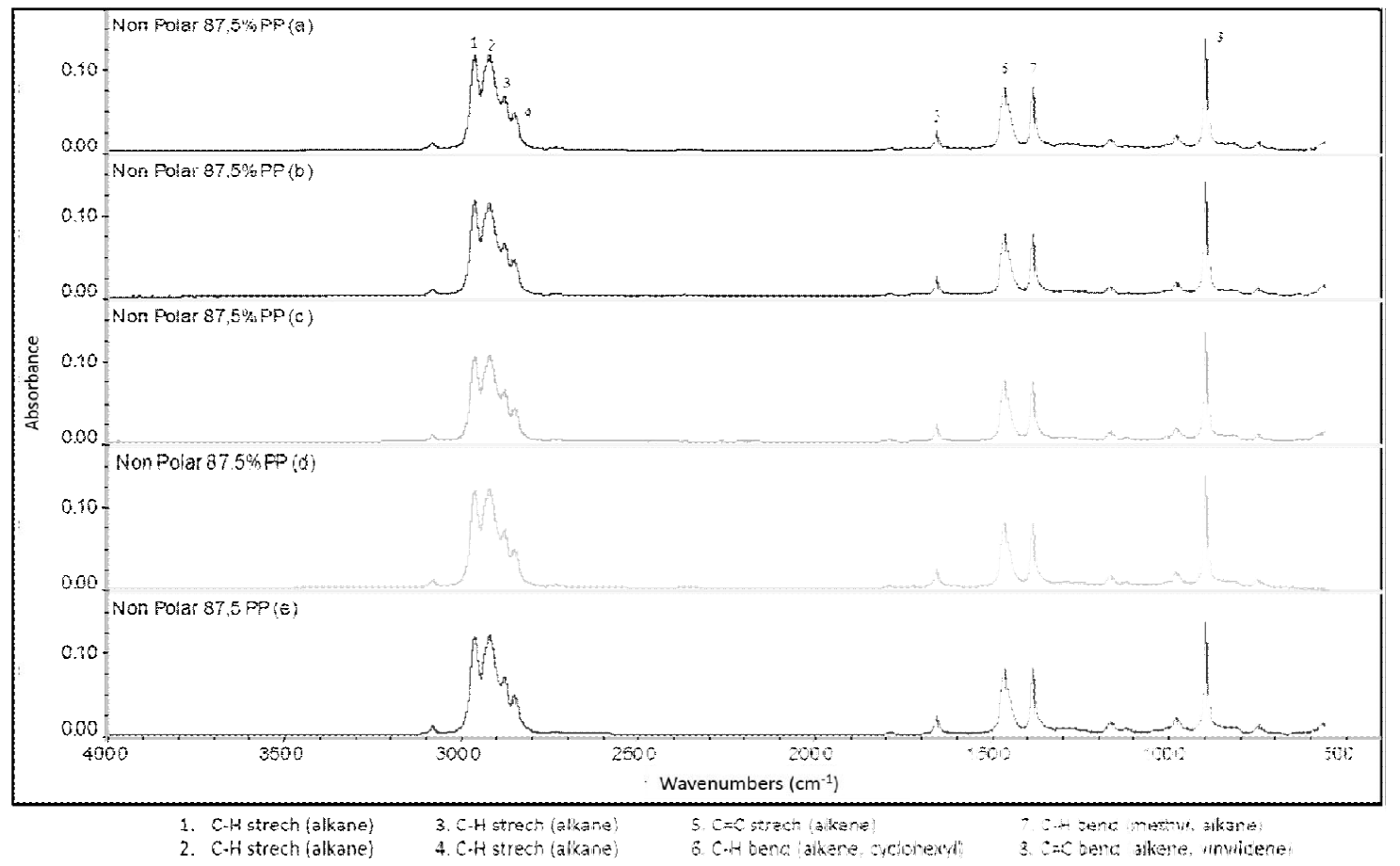

Fig. 2. FT-IR spectra of bio-oil from the first-stage pyrolysis 


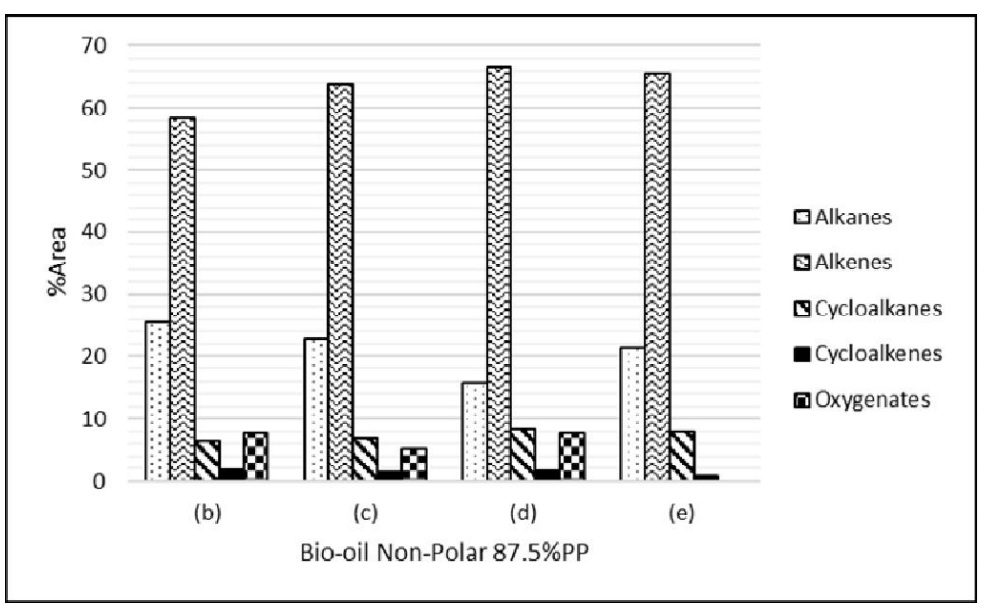

Fig. 3. Aliphatic composition of bio-oil produced by the first-stage pyrolysis

\subsection{Second-Stage Pyrolysis Bio-oil Characterization}

The kinematic viscosity of the bio-oil obtained from the second-stage pyrolysis was tested at $40^{\circ} \mathrm{C}$ and the measured viscosities of bio-oil obtained from the second-stage pyrolysis respectively are shown in Fig. 5. Viscosity of commercial gasoline and diesel measured for comparison are respectively 0.7 cStokes and 2.7 cStokes [9]. The viscosities of bio-oil resulting from the second-stage pyrolysis with the final temperatures of $200^{\circ} \mathrm{C}$ and $300^{\circ} \mathrm{C}$ were closer to the viscosity of gasoline. Viscosity of bio-oil from pyrolysis with the final temperature of $375^{\circ} \mathrm{C}$ was in between the viscosities of gasoline and diesel, while that from pyrolysis with the final temperature of $450^{\circ} \mathrm{C}$ was closer to the viscosity of diesel.

The bio-oil sampled from the second-stage pyrolysis were also characterized using GC-MS, LC-MS and HNMR. Because of the low yield of bio-oil obtained from the pyrolysis with the final temperature of $200^{\circ} \mathrm{C}$, this bio-oil was characterized using GC-MS and LC-MS only.
Fig. 6 shows that the compounds detected by GCMS mostly were of alkenes. The bio-oil characterization by H-NMR is shown in Table 1. H-NMR result shows that bio-oil resulting from pyrolysis with the final temperature of $300^{\circ} \mathrm{C}, 375^{\circ} \mathrm{C}$ and $450^{\circ} \mathrm{C}$ contained protons bonded to $\mathrm{C}=\mathrm{C}$ chains respectively amounting to 7.03 , 6.97, and $6.43 \%$, which means that alkenes had much less composition than alkanes. The result of $\mathrm{H}$ NMR differs from that of GC-MS because H-NMR can detect proton at alkanes with high molecular weights or long carbon chains which cannot be detected by GC-MS $[13,14]$. The reduction of alkene composition in bio-oil resulting from pyrolysis with higher final temperature means that higher temperature of the pyrolysis was unable to make more cracking on aliphatic chains, which is not expected. It seems there were condensation or polymerization reactions between double-bond carbon chains in competition with the cracking reactions [15]. It is suspected that the rate of polymerization reaction at higher temperature was higher than the rate of cracking reactions leading to net reduction of alkenes produced as suggested by Fig. 5 where higher final temperature in the second-stage pyrolysis produced bio-oil with higher viscosity.

Table 1. H-NMR analysis of bio-oil and gasoline

\begin{tabular}{|c|c|c|c|c|c|c|}
\hline \multirow[t]{2}{*}{ Hydrogen Types } & \multirow[t]{2}{*}{$\begin{array}{l}\text { Chemical } \\
\text { Shift }\end{array}$} & \multirow{2}{*}{$\begin{array}{c}\text { \% Amount of } \\
\text { Protons in Bio- } \\
\text { oil from First- } \\
\text { Stage } \\
\text { Pyrolysis }\end{array}$} & \multicolumn{3}{|c|}{$\begin{array}{c}\text { \% Amount of Protons in Bio-oil from } \\
\text { Second-Stage Pyrolysis Temperature } \\
\text { of }(\%)\end{array}$} & \multirow[t]{2}{*}{$\begin{array}{c}\% \% \\
\text { Amount of } \\
\text { Protons in } \\
\text { Gasoline }\end{array}$} \\
\hline & & & $300^{\circ} \mathrm{C}$ & $375^{\circ} \mathrm{C}$ & $450^{\circ} \mathrm{C}$ & \\
\hline Aromatics & $7.2-6.0$ & 0 & 0 & 0.01 & 0 & 8.83 \\
\hline Proton at $\mathrm{C}=\mathrm{C}$ & $6.0-4.5$ & 6.03 & 7.03 & 6.97 & 6.43 & 0.74 \\
\hline $\begin{array}{l}\text { Proton at } \mathrm{OCH}_{3} \text { group bonded to } \\
\text { guaiacyl, syringyl and lignin linkage }\end{array}$ & $4.5-3.3$ & 0 & 0.03 & 0.01 & 0.02 & 0 \\
\hline Proton at $\alpha-\mathrm{C}$ bonded to $\mathrm{C}=\mathrm{C}$ & $3.3-1.8$ & 17.82 & 23.24 & 22.38 & 20.52 & 18.14 \\
\hline Methyne (CH) & $1.8-1.4$ & 8.70 & 5.46 & 5.81 & 7.42 & 4.40 \\
\hline Methylene $\left(\mathrm{CH}_{2}\right)$ & $1.4-1.1$ & 15.11 & 16.50 & 15.94 & 15.71 & 24.75 \\
\hline Methyl $\left(\mathrm{CH}_{3}\right)$ & $1.1-0.4$ & 52.35 & 47.75 & 48.88 & 49.90 & 43.14 \\
\hline
\end{tabular}




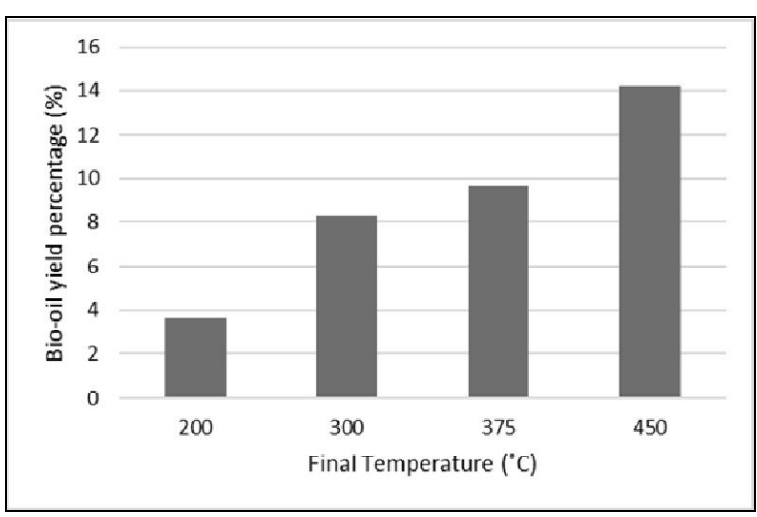

Fig. 4 Bio-oil yields in the second-stage pyrolysis at different final temperatures.

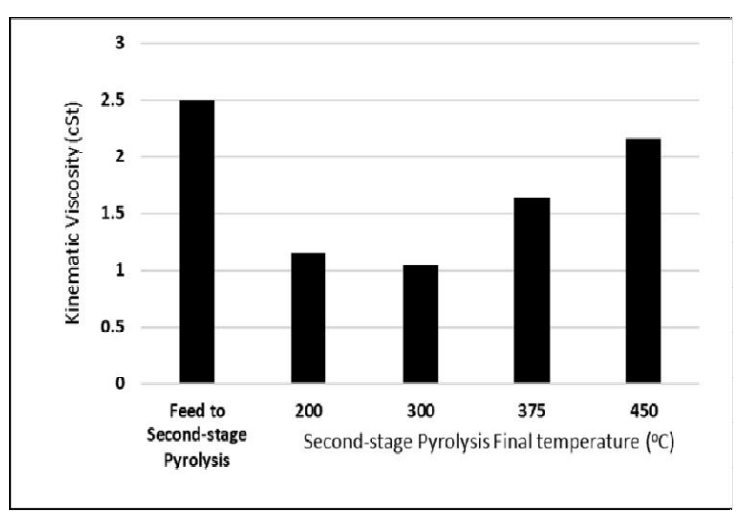

Fig. 5. Kinematic viscosity of bio-oil from the second-stage pyrolysis

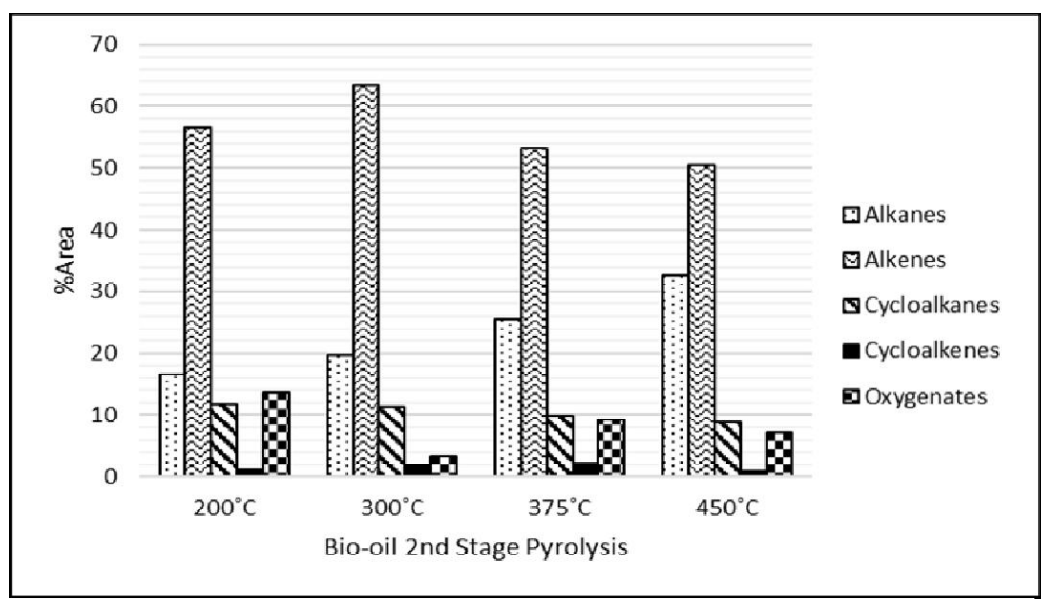

Fig. 6. Aliphatic composition of bio-oil from the second-stage pyrolysis

Comparing H-NMR analysis of the first-stage and the second-stage pyrolysis (see Table 2), combined proton composition attributed to methyl, methylene and methane, which represented alkanes in bio-oil, from the second-stage was lower than that from the first-stage pyrolysis, and consequently the composition of protons attributed to alkenes was higher. It suggests that in the second pyrolysis broken carbon chains resulted in more double bond carbon chains under condition of lack of external hydrogen radical donation.

Oxygenate compounds associated to proton in the $\mathrm{H}$ NMR result was very low (below $0.05 \%$ ). This might have happened as long carbon chains, which had small polarity, were soluble in non-polar fraction when the separation of polar and non-polar fractions occurred.

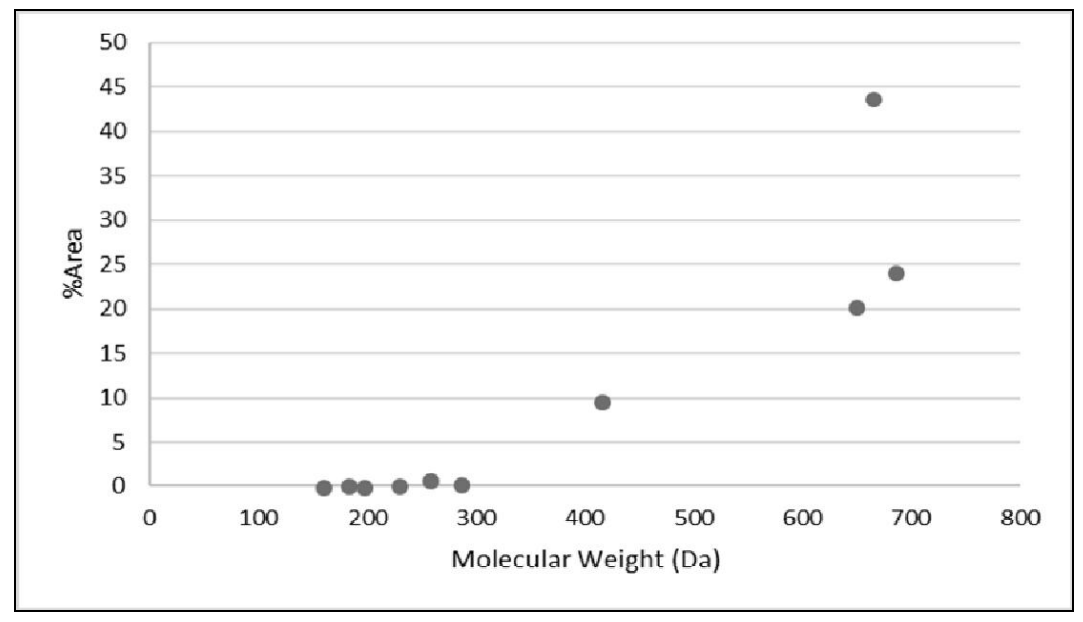

Fig. 7. Molecular weight distribution of bio-oil from first-stage pyrolysis 


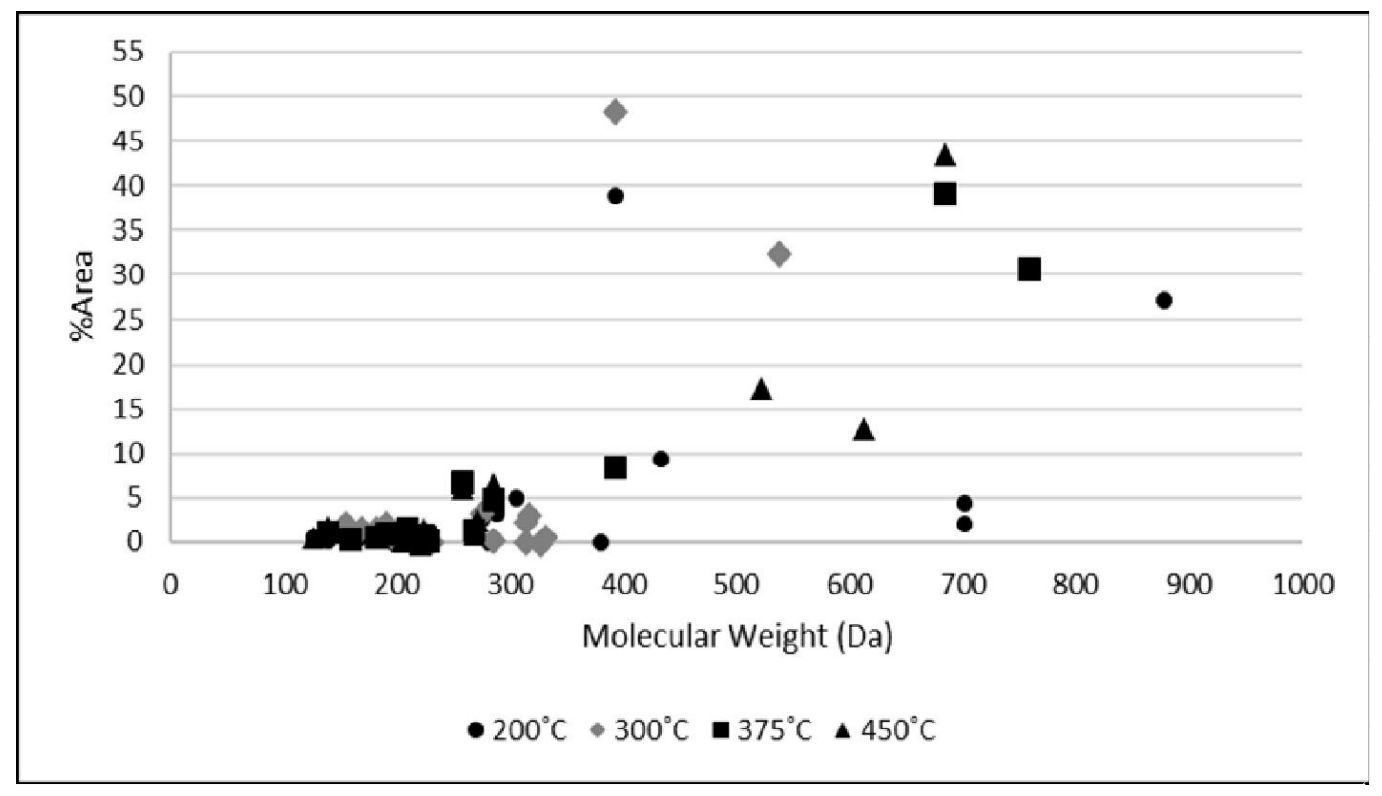

Fig. 8. Molecular weight distribution of bio-oil from second-stage pyrolysis

\subsection{Molecular Weight Distribution of Bio-oil}

Molecular weight distribution of bio-oil obtained by the first-stage pyrolysis is shown in Fig. 7, while for secondstage pyrolysis is shown in Fig. 8. The distribution data were obtained from LC-MS measurement, which can analyze the whole contents of bio-oil because LC-MS was capable of detecting high molecular weight compounds. Fig. 7 shows that the first-stage pyrolysis \%area was dominated by molecular weight around 663 $\mathrm{Da}, 684 \mathrm{Da}$ and $647 \mathrm{Da}$, with \%area respectively $43.79 \%, 24.22 \%$ and $20.45 \%$. Fig. 8 shows that at low molecular weights, all the second-stage pyrolysis bio-oil samples exhibit very low $\%$ area. However, as the molecular weight more than $400 \mathrm{Da}$, those samples demonstrated some differences. For example, bio-oil obtained from pyrolysis with final temperature of $200^{\circ} \mathrm{C}$, \%area was dominated by molecular weight around 391 $\mathrm{Da}$ and $876 \mathrm{Da}$, with \%area respectively $39.07 \%$ and $27.45 \%$. The bio-oil product from pyrolysis with final pyrolysis temperature of $300^{\circ} \mathrm{C}$ was dominated by molecular weight around $391 \mathrm{Da}$ and $536 \mathrm{Da}$, with $\%$ area respectively $48.52 \%$ and $32.47 \%$. It means that the average molecular weight of bio-oil from pyrolysis at $300^{\circ} \mathrm{C}$ was smaller than that at $200^{\circ} \mathrm{C}$. This may have resulted that the earlier bio-oil had slightly lower viscosity than the latter bio-oil (see Fig. 5).

As the pyrolysis was carried out with final temperature of $375^{\circ} \mathrm{C}$, the predominant molecular weights were around $758 \mathrm{Da}$ with \%area of $30.77 \%, 683$ Da with \%area of $39.19 \%$ and 395 Da with \%area of $8.3 \%$. For the bio-oil obtained by pyrolysis with final temperature of $450^{\circ} \mathrm{C}$, the predominant molecular weights were around 520 Da with \%area of $16.53 \%, 611$ Da with \%area of $13 \%$ and 683 Da with \%area of
$43.76 \%$. These data of molecular weights show that the molecular weight distribution of bio-oil with final temperature of $375^{\circ} \mathrm{C}$ was more spreading than that of $450^{\circ} \mathrm{C}$. The more concentrated molecular weight distribution of bio-oil with final temperature of $450^{\circ} \mathrm{C}$ seems to give higher viscosity than that of bio-oil with final temperature of $375^{\circ} \mathrm{C}$. As far as the branching index is concerned, the earlier bio-oil had lower index than that of the latter bio-oil (see Table 2). Consequently, combined methylene and methyne groups in the earlier bio-oil were distributed in less number of carbon chains and gave in average longer branching. According to Khare et al [16] found that long branching attenuates the oil viscosity. Confronting the results above of the effect of molecular weight distribution and branching index on bio-oil viscosity, it suggests that the molecular weight distribution exerts more influence on the bio-oil viscosity.

Comparing the molecular weights of bio-oil obtained from the second-stage pyrolysis with final temperatures of 300 and $375^{\circ} \mathrm{C}$ exhibited in Fig. 8 shows the earlier had lower maximum molecular weight than the latter with significant difference. This may have resulted in viscosity difference, where the earlier was smaller than the latter.

\subsection{Bio-oil and Gasoline Characteristics Comparison}

To see whether the bio-oil has achieved similar characteristics to gasoline, the viscosity, BI, and HHV of bio-oil was compared to gasoline. The comparison is shown in Table 2. 
Table 2. Comparison between bio-oil and gasoline

\begin{tabular}{|l|c|c|c|c|c|}
\hline \multirow{2}{*}{ Requirements } & \multirow{2}{*}{$\begin{array}{c}\text { First- } \\
\text { stage } \\
\text { Bio-oil }\end{array}$} & \multicolumn{3}{|c|}{ Second-stage Bio-oil } & \multirow{2}{*}{$\mathbf{C}$} \\
\cline { 3 - 6 } & $\mathbf{3 7 5}^{\circ} \mathbf{C}$ & $\mathbf{4 5 0}^{\circ} \mathbf{C}$ & Gasoline \\
\hline $\begin{array}{l}\text { Kinematic } \\
\text { Viscosity (cSt) }\end{array}$ & 2.5 & 1.05 & 1.63 & 2.16 & 0.7 \\
\hline Branching Index & 1.47 & 1.45 & 1.50 & 1.44 & 0.99 \\
\hline $\begin{array}{l}\text { Higher Heating } \\
\text { Value, HHV } \\
\text { (MJ/kg) }\end{array}$ & 47.36 & 47.46 & 47.45 & 47.40 & 54.57 \\
\hline
\end{tabular}

Gasoline has branching index as well as kinematic viscosity lower than indices and viscosities attributed to bio-oil obtained from the second-stage pyrolysis. Considering the finding by Khare et al [16] that long branches, corresponding to low branching index, attenuates kinematic viscosity, it suggests that it is not molecular weight distribution inducing low viscosity of gasoline, but branching index. Therefore, effort of synthetizing bio-oil with characteristics approaching to those of gasoline should be directed to diminishing the branching index.

Table 2 shows that HHV values of all bio-oil samples had similar values and their values are close to gasoline's HHV value. For comparison, HHV value of bio-oil obtained from biomass pyrolysis has value around 18-26 MJ/kg because of containing a lot oxygenate compounds [14]. Based on the H-NMR data (see Table 1), the experimental bio-oil had low oxygenate compounds and consequently high $\mathrm{HHV}$ value.

\section{Conclusion}

From the analyzed data, it can be concluded that in order to obtain high yield of bio-oil, the second-stage pyrolysis be carried out under heating until a final temperature beyond the highest temperature of mass decomposition according to TGA data of bio-oil feed $\left(375^{\circ} \mathrm{C}\right)$. However, the pyrolysis produced bio-oil with viscosity even larger than that of gasoline. The second-stage pyrolysis with final temperature of $300^{\circ} \mathrm{C}$ was the optimum temperature for obtaining bio-oil similar to gasoline because it has the lowest kinematic viscosity despite of highest alkenes composition according to $\mathrm{H}$ NMR and low yield of bio-oil. It is recommended to do second-stage pyrolysis simultaneously with hydrogenation of the separated non-polar bio-oil to attain biofuel similar to gasoline.

Comparison of data of viscosities and branching indices of bio-oil obtained from the second-stage pyrolysis and gasoline suggests that in order to lower the bio-oil viscosity, the pyrolysis may be performed in coinciding with attempt of reducing branching index.
Authors would express their gratitude for the financial support of the present work by PITTA (Publikasi Terindeks Internasional untuk Tugas Akhir Mahasiswa) scheme for budget year 2018 with contract number 2483/UN2.R3.1/HKP.05.00/2018. The scheme was granted by Universitas Indonesia.

\section{References}

1. General Secretariat of Indonesia Energy Council, Indonesia Energy Outlook (2016)

2. IRENA, Biofuel Potential in Southeast Asia: Raising food yields, reducing food waste and utilising residues, International Renewable Energy Agency, Abu Dhabi (2017)

3. D. Supramono, Jonathan, Haqqyana, Setiadi, M Nasikin, Improving Bio-oil Quality Through CoPyrolysis of Corn Cobs and Polypropylene in a Stirred Tank Reactor. International Journal of Technology 8, 1381-1391 (2016)

4. Q. Lu, W. Li, X. Zhu, Overview of Fuel Properties of Biomass Fast Pyrolysis Oils, Energy and Conversion and Management 50, 5, 1376-1383 (2009)

5. M.E. Boucher, A. Chaala, C. Roy, Bio-oils Obtained by Vacuum Pyrolysis of Softwood Bark as a Liquid Fuel for Gas Turbines. Part I: Properties of Bio-oil and Its Blends with Methanol and a Pyrolytic Aqueous Phase. Biomass and Bioenergy 19, 337 (2000).

6. S. Kumar, R.K. Singh, Conversion of Waste High Density Polyethylene into Liquid Fuels. PhD Thesis, National Institute of Technology Rourkela (2013).

7. F. Abnisa, W.M.A. Wan Daud, A Review on Copyrolysis of Biomass: An Optional Technique to Obtain a High-Grade Pyrolysis Oil, Energy Conversion and Management 87, 71-85 (2014)

8. H. Yang, R. Yan, H. Chen, D.H. Lee, C. Zheng, Characteristics of Hemicellulose, Cellulose and Lignin Pyrolysis, Fuel 86, 1781-1788 (2007)

9. D. Supramono, Julianto, Haqqyana, H Setiadi, M Nasikin, Phase Separation of Bio-oil Produced by Co-pyrolysis of Corn Cobs and Polypropylene, IOP 93 (2017).

10. G. Yan, X. Jing, H. Wen, S. Xiang, Thermal Cracking of Virgin and Waste Plastics of PP and 
LDPE in a Semibatch Reactor under Atmospheric Pressure, Energy \& Fuels, 29, 2289 (2015).

11. D.V. Naik, V. Kumar., B. Prasad, M.K. Poddar, B. Behera, R. Bal, O.P. Khatri, D.K. Adhikari, M.O. Garg, Overview of Fuel Properties of Biomass Fast Pyrolysis Oils, Energy Conversion and Management, 5, 389 (2015).

12. S.A. Channiwala, P.P. Parikh, A Unified Correaltion for Estimating $\mathrm{HHV}$ of Solid, Liquid and Gaseous fuels. Fuel, 81, 1051 (2002).

13. V.I. Sharypov, N.G. Beregovtsova, B.N. Kuznetsov, L. Membrado, V.L. Cebolla, N. Marin, J.V. Weber, Co-pyrolysis of Wood Biomass and Synthetic Polymers Mixtures. Part III: Characterisation of Heavy Products, J. Anal. Appl. Pyrolysis 67, 333 (2003)

14. S. Nanda, P. Mohanty, J.A. Kozinski, A.K. Dalai., Physico-Chemical Properties of Bio-Oils from Pyrolysis of Lignocellulosic Biomass with High and Slow Heating Rate, En. and Env. Res. 4, 27 (2014)

15. R. Vinu, L.J. Broadbelt, Unraveling Reaction Pathways and Specifying Reaction Kinetics for Complex Systems, Annu. Rev. Chem. Biomol. Eng., 3, 29-54 (2012)

16. R. Khare, J. de Pablo, Rheological, Thermodynamic, and Structural Studies of Linear and Branched Alkanes under Shear, J. Chem. Phys., 107, 6956 (1997) 